Revista Perspectivas Online: Humanas \& Sociais Aplicadas

Fevereiro de 2020, v.10, n.27, p. 33-45 ISSN: 2236-8876(Online)

DOI: $10.25242 / 8876102720201730$

\title{
INSTRUMENTOS INFORMATIVOS DE EDUCAÇÃO AMBIENTAL E SANITÁRIA APLICADOS NA SOCIEDADE
}

\author{
Bruna Magalhães de Araujo ${ }^{1}$, Ana Silvia Pereira dos Santos ${ }^{1}$, Frank Pavan $^{2}$ \& Marília \\ Carvalho de Melo ${ }^{3}$
}

\section{RESUMO}

ARAUJO, B. M.; SANTOS, A. S. P.; PAVAN, F.; MELO M.C. Instrumentos informativos de educação ambiental e sanitária aplicados na sociedade. Perspectivas Online: Humanas \& Sociais Aplicadas, v.10, n.27, p.33-45, 2020.

Diante da importância do saneamento e sua universalização, para a promoção do bem estar da população, saúde pública e proteção do meio ambiente, é essencial ações que contribuam para o envolvimento da população com o tema. Neste sentido, é importante avaliar quais são os instrumentos informativos expressivos, que atuam no saneamento e seu alcance na população em geral. Assim, o presente estudo teve como objetivo discutir os instrumentos informativos existentes como SNIS, ATLAS Esgotos e Instituto Trata Brasil, acerca da educação ambiental e sanitária de modo a contribuir para o efetivo cumprimento das metas de saneamento. Para tanto foi desenvolvida uma metodologia na qual foram atribuídos pontos, de forma subjetiva, de acordo com as variáveis definidas:acessibilidade, clareza de linguagem, qualidade dos dados, abrangência, divulgação e qualidade das imagens. Desta forma, para avaliações consideradas ruim, regular, boa e ótima foi admitida pontuação de $1,2,3$ e 4 respectivamente. A partir dos resultados encontrados no presente trabalho, foi possível constatar que o SNIS apresentou menor pontuação, com 11 de 24, o Atlas Esgotos atingiu avaliação regular, com 20 de 24 pontos. Já o Instituto Trata Brasil alcançou maior pontuação, com 23 de 24 e demonstrou maior comprometimento e eficácia em promover a informação e conscientização da população, nos assuntos relacionados ao saneamento.

Palavras-chave:Saneamento, Educação Ambiental; instrumentos informativos. 


\begin{abstract}
The importance of health and its universalization, public health and protection of the environment, the contribution to the involvement of the population with the theme. This sense, which is relevant there are instrumental informative expressive, which act non sanitation and your reach in the populace in general. The objective of this study was to obtain information tools such as SNIS, ATLAS Sewage and Institute Trata Brasil, on environmental and sanitary education in order to contribute to the effective fulfillment of the sanitation goals. For the proposed in the minimum already have the points of the following points, have been

defined for variable settings: accessibility, clarity in the language, quality of date, comprehensiveness, advertising and quality of images. In this way, to make the comparison, regular, good and excellent was included in 1, 2, 3 and 4 respectively. From the results found it was not possible, it was possible to verify that the SNIS presented a lower score, with 11 of 24 , the Atlas achieved the regular evaluation, with 20 of 24 points. The Institute Trata Brasil reached the highest level, with 23 of 24 and showed greater commitment and promotion of information and awareness of the population, in the topics related to sanitation.
\end{abstract}

Keywords: Sanitation; EnvironmentalEducation; informationtools

\footnotetext{
${ }^{1,}$ Universidade Estadual do Rio de Janeiro (UERJ) - Departamento de Engenharia Ambiental. Campus Maracanã, Rio de Janeiro RJ. CEP: 20550-000, Brasil;

${ }^{2}$ Institutos Superiores de Ensino do CENSA - ISECENSA - Rua Salvador Correa, 139, Centro, Campos dos Goytacazes, RJ, CEP: 28035-310, Brasil;

${ }^{3}$ Instituto Mineiro de Gestão das Águas (IGAM). Cidade Administrativa do Estado de Minas Gerais - Serra Verde, Belo Horizonte - MG. Brasil

(*)e-mail: frank@acionaconsultoria.com.br

Data de recebimento:03/05/2019.Aceito para publicação:17/02/2020.
}

Persp. Online: hum \& sociais aplicada., Campos dos Goytacazes, 27 (10)33-45- 2020

seer.perspectivasonline.com.br 


\section{INTRODUÇÃO}

A complexidade ambiental, social e econômica vivida por parte da população brasileira, que não possui os serviços de atendimento básico de saneamento, como por exemplo abastecimento de água tratada, coleta e tratamento de esgoto e gestão de resíduos sólidos, pode estar associada ao ambiente em que habitam, e que por vezes podem afetar de forma negativa à sua saúde. Geralmente, as áreas ocupadas por esses grupos, são espaços que vêm sendo utilizados por gerações e podem encontrar-se em condições precárias no que diz respeito aos serviços básicos citados anteriormente (CARVALHO et al, 2018).

Segundo a Lei federal de $\mathrm{n}^{\mathrm{o}} 11.445 / 2007$, conhecida como a lei do Saneamento Básico, pode-se definir como Saneamento o conjunto de serviços, infraestruturas e instalações de abastecimento de água, esgotamento sanitário, limpeza urbana e manejo de resíduos sólidos e drenagem de águas pluviais urbanas. Tal legislação estabelece as diretrizes nacionais para o setor, e institui como princípio a universalização do saneamento. O contato com esgoto bruto e o consumo de água sem tratamento adequado estão diretamente relacionados com propagação de doenças e altas taxas de mortalidade infantil. Segundo o Instituto Trata Brasil (2019), 361 mil crianças menores de 5 anos morrem em razão de diarreia, em função do baixo acesso à água tratada, ao saneamento e a condições inadequadas de higiene. Sabe-se que o saneamento atua na redução do impacto ambiental, prevenção de doenças e promoção da qualidade de vida, além de ser um direito assegurado pela legislação em questão. Neste sentido, fica explicito a importância do Saneamento como ferramenta básica fundamental na promoção da saúde pública e proteção do meio ambiente, além de influenciar significativamente na economia e desenvolvimento humano e social de um país.

Entre os princípios fundamentais estabelecidos pela lei do saneamento básico, a transparência das ações, baseada em sistemas de informações e processos decisórios institucionalizados e o controle social, se destacam por estarem intrinsicamente relacionados com a promoção de informações a população. Sabe-se que o envolvimento da população nos assuntos relacionados ao Saneamento e Meio Ambiente são requisitos básicos e decisórios para evolução do tema em questão. Além disso, a participação dos indivíduos propicia a transformação do valor atualmente dado ao setor no território nacional, em prioridade e, corrobora a sua inclusão efetiva na gestão e planejamento das cidades. Neste contexto, a educação Ambiental torna-se uma importante ferramenta de aproximação e integração entre os cidadãos, gestores e o tema. Para que isto ocorra é necessário que as informações pertinentes sejam transmitidas por meio de uma metodologia acessível a todos os cidadãos, de maneira clara, objetiva e transparente.

De acordo com o art. $1^{\circ}$ da Lei Federal de $n^{\circ} 9.795$ de 1999, que trata sobre a educação ambiental e institui sua Política Nacional de Educação Ambiental, educação ambiental compreende:

\footnotetext{
os processos por meio dos quais o indivíduo e a coletividade constroem valores sociais, conhecimentos, habilidades, atitudes e competências voltadas para a conservação do meio ambiente, bem de uso comum do povo, essencial à sadia qualidade de vida e sua sustentabilidade.
}

Para isso, o poder público, as intuições de ensino, órgãos do Sistema Nacional do Meio Ambiente no Brasil (SISNAMA), meios de comunicação em massa, empresas e sociedade, possuem papeis importantes de maneira a atingir tais objetivos

Em especial, os órgãos do SISNAMA, objetivam promover ações de educação Ambiental. Como é o caso do o ATLAS Esgotos: Despoluição de Bacias Hidrográficas, 
publicado pela Agência Nacional de Águas (ANA) em 2017, e do Sistema Nacional de Informações sobre Saneamento (SNIS). Ha ainda de se destacar as ações realizadas pelos meios de comunicações, como o instituto Trata Brasil, que se utiliza das mídias sociais tais como página de internet e Instagram com a finalidade de difundir informações sobre saneamento aos cidadãos.

Vale ressaltar o entendimento de Pavan et. al (2016) quando relata a importância das diretrizes do saneamento como parte integrante de um bem ambiental e a preocupação com a escassez da água, para as gerações futuras, expõe problemas ambientais existentes ligados a má utilização da água.

Em face do exposto anteriormente e visto que a população, configura-se como um importante e decisivo agente regulador a respeito da cobertura e qualidades dos serviços de saneamento básico, torna-se essencial implantar medidas que garantam o acesso as informações sobre saneamento e meio ambiente. E para tanto é fundamental analisar as ferramentas mais relevantes e expressivas utilizadas atualmente, de modo a possibilitar o entendimento do que pode ser melhorado. Assim, o presente trabalho objetivou discutir sobre a existência de instrumentos informativos acerca da educação ambiental e sanitária de modo a contribuir para o efetivo cumprimento das metas de saneamento no Brasil.

\section{METODOLOGIA}

O presente trabalho foi desenvolvido a partir da análise da influência de três principais fontes de informação sobre o saneamento ambiental no Brasil. São elas: SNIS, Trata Brasil e ATLAS Esgotos. A seguir serão detalhados os instrumentos informativos utilizados no estudo.

Em 1996, o Governo Federal criou o Sistema Nacional de Informações sobre Saneamento (SNIS). A princípio foram coletados dados referentes somente aos prestadores de serviços de água e esgotos, porém posteriormente, em 2002, foram adicionados dados referentes aos resíduos sólidos. Finalmente em 2016, o componente de Águas Pluviais Urbanas passou também a incorporar a base de dados. Destaca-se que o sistema em questão tem por objetivo constituir-se como uma ferramenta capaz de auxiliar no planejamento e execução de políticas públicas de saneamento; orientação da aplicação de recursos;conhecimento e avaliação do setor saneamento;avaliação de desempenho dos prestadores de serviços;aperfeiçoamento da gestão;orientação de atividades regulatórias e de fiscalização; eexercício do controle social. Para tanto foram obtidas informações junto aos prestadores de serviçoatualizados anualmente e disponibilizados gratuitamente a qualquer interessado. Anualmente a plataforma divulga o Diagnóstico dos Serviços de Água e Esgotos que está em sua vigésima terceira edição, além do Diagnóstico de Manejo dos resíduos sólidos Urbanos que hoje está em sua decima sexta edição, ambos com sua última edição publicada em 2019, com dados referentes ao ano de 2017.

Já o Instituto Trata Brasil, é constituído como uma Organização da Sociedade Civil de Interesse Público, integrada por empresas com interesse nos avanços do saneamento básico e na proteção dos recursos hídricos nacionais, com atuação desde 2007. O instituto possui o objetivo de informar os cidadãos, de forma que os mesmos sejam capazes de reivindicar a universalização dos serviçosde saneamento básico. Para isso, o Instituto Trata Brasil utiliza sua web site e disponibiliza em sua página, o Manual do Saneamento, Boletim Trata Brasil, Cartilha da turma da Monica dedicada a conscientizar o público infantil, entre outros materiais destinados a informar o público em geral. Além disso, a organização possui um

Persp. Online: hum \& sociais aplicada., Campos dos Goytacazes, 27 (10)33-45- 2020 seer.perspectivasonline.com.br 
perfil noInstagram, FacebookeTwitter.

Mais recentemente, em 2017 diante do desafio enfrentado na área de saneamento, a ANA e Secretaria Nacional de Saneamento Ambiental do Ministério das Cidades (SNSA/MCidades) somaram esforços no intuito de ampliar o conhecimento a respeito dos sistemas de esgotamento sanitário nos municípios brasileiros. Assim, surgiu o ATLAS Esgotos: Despoluição de Bacias Hidrográficas. Posteriormente, em 2018 foi lançado o aplicativo Água e Esgoto que objetivava aumentar o alcance das informações transmitidas e popularidade entre os cidadãos.O Atlas Esgotos apresenta uma analise da situação do esgotamento sanitário das 5.570 cidades brasileiras e dos impactos do lançamento dos esgotos nos rios, lagos e reservatórios do País. Tal instrumento informativo, tem por objetivos, caracterizar a situação do esgotamento sanitário em todos os municípios brasileiros, avaliar o impacto do lançamento dos esgotos nos corpos d'água, propor soluções de coleta e tratamento de esgotos com foco na universalização dos serviços e no atendimento aos usos múltiplos da água, propor estratégia de caráter técnico e institucional para orientar os processos de planejamento, regulação e financiamento no âmbito dos setores de recursos hídricos e saneamento e disponibilizar à sociedade e aos tomadores de decisão informações de todas as cidades brasileiras, de forma a fortalecer os processos de planejamento e gestão de recursos hídricos e de saneamento.

Para cada um desses instrumentos informativos foram avaliadas as seguintes variáveis, de maneira subjetiva:

- Acessibilidade: Em um universo globalizado, onde as informações são transmitidas rapidamente, por diferentes meios, o acesso dos dados pode ser realizado de diversas formas, sejam elas: livros, revistas, web sites, redes sociais (Instagram, Facebook, e etc), dentre outros. Modernamente, os veículos de informação transmitidos pela internet, em geralpossuemalta abrangência e boa aceitação dos indivíduos, além de sua rapidez e alcance. Já os livros e revistas por sua vez, embora sejam essenciais no universo acadêmico, não conseguem atingir os cidadãosque não atuam no setor. Neste sentido, para este item foi avaliada a acessibilidade dos instrumentos de informação, utilizados no presente trabalho, à população em geral.

- Clareza de linguagem: Diante do objetivo de realizar uma real e efetiva disseminação das informações de saneamento para todo e qualquer individuo e provocar um envolvimento maior da população com o tema, é importante que os instrumentos informativos apresentem uma linguagem condizente e adequada para este fim. Assim, para este item foi avaliado se os autores conseguiram transmitir as informações com uma linguagem clara e acessível à população em geral, não se atendo somente a termos técnicos e rebuscados de difícil entendimento para indivíduos que não atuam no setor.

- Qualidade dos dados: Além da disseminação e clareza na linguagem utilizada, a qualidade dos dados é fundamental para que a população seja informada de maneira adequada e efetiva, combatendo a disseminação de informações incorretas, que atrapalham a evolução do setor. Para tanto, este item avalia a origem dos dados e sua confiabilidade.

- Abrangência: Para que os dados cheguem a todo e qualquer público, é importante que as ferramentas de informação utilizadas possuam um alcance significativo e eficiente a população. Para este item foi analisado o número de downloads nos aplicativos, quantidade de seguidores em redes sociais, número de postagens, dentre outros parâmetros cabíveis aos web sites.

Persp. Online: hum \& sociais aplicada., Campos dos Goytacazes, 27 (10)33-45- 2020 
- Divulgação: Para que a população tenha conhecimento das existências dos respectivos instrumentos de informação, analisados no presente estudo, é importante que os mesmos sejam divulgados nos meios de comunicação de maneira eficiente. Assim, no referido item, foi analisado a quantidade e qualidade das matérias publicadas.

- Qualidade de imagens: Sabe-se que a imagem é uma importante ferramentade comunicação, visto que a informação desejada deve ser transmitidade maneira a ser interpretada intuitivamente, com o auxílio de títulos e legendas adequados, sem causar dúvidas, ou interpretações incorretas. Nesse contexto, este item foi destinado a avaliar se os instrumentos de informaçãoestudados no presente trabalho, utilizaram imagens, nítidas, de fácil interpretação ao público em geral e correspondentes aos objetivos de cada trabalho.

Posteriormente, para cada um dos instrumentos informativos foram atribuídos pontos de acordo com variáveis avaliadas. Nos itens considerados com a avaliação ruim, foi admitida uma unidade de pontuação, para regular duas unidades, no caso de uma avaliação considerada boa foi admitido três unidades e por fim, para variáveis consideradas ótimas, foi atribuído quatro unidades de pontuação. Em seguida foram discutidas as características específicas de cada instrumento em relação às variáveis abordadas.

\section{RESULTADOS E DISCUSSÃO}

Na Tabela 1, é possível observar a avaliação realizada para os Instrumentos de informação SNIS, Atlas Esgotos e Trata Brasil, de acordo com o sistema de pontuação apresentado na metodologia do presente trabalho.

Tabela 1: Avaliação dos Instrumentos de informativos de educação ambiental e sanitária aplicados na sociedade. Fonte: O autor, 2019.

\begin{tabular}{lccc}
\hline \multicolumn{1}{c}{ Variáveis } & SNIS & Trata Brasil & Atlas Esgotos \\
\hline Acessibilidade & 2 & 4 & 3 \\
Clareza de linguagem & 2 & 4 & 3 \\
Qualidade dos dados & 3 & 3 & 4 \\
Abrangência & 1 & 4 & 3 \\
Divulgação & 1 & 4 & 3 \\
Qualidade de imagens & 2 & 4 & 4 \\
Total & 11 & 23 & 20 \\
\hline
\end{tabular}

A partir da Tabela apresentada, é possível observar que no que tange a variável acessibilidade o SNIS apresentou pontuação inferior, quando comparado aos demais instrumentos. Isto porque o SNIS apresenta sua web site como único veículo de informação, enquanto que o Trata Brasil possui além de sua web site, um Blog e perfis no Twitter, Instagram, Facebook, YouTube e linkedIn. Já o Atlas esgotos publicada pela ANA, embora não apresente perfis em redes sociais, possui sua página na Internet e uma versão mobile, disponível tanto para Android como para $i O S$ que facilita o acesso e compreensão dos estudos que apoiam a gestão dos recursos hídricos. 
Com relação a clareza de linguagem, o Instituto Trata Brasil, apresentou melhor avaliação, de acordo com as premissas estabelecidas nesta variável. Além de apresentar uma linguagem adequada e destinada ao público em geral, os veículos de informação utilizados neste instrumento fazem uso de palavras chaves simples que chamam atenção dos cidadãos não técnicos. Já o Atlas Esgotos, apresenta um vocabulário mais técnico, com palavras como Demanda Bioquímica de Oxigênio (DBO), carga de esgoto, soluções individuais, dentre outros, que dificultam o entendimento do público que não trabalha no setor. O SNIS por sua vez apresenta um vocabulário extremamente técnico composto por palavras como macromedição, hidrometração, turbidez, liquidez corrente, margem líquida, dentre outros e por isso, para o instrumento foi atribuído a menor pontuação, neste item.

A variável qualidade dos dados, foi avaliada a partir da origem das informações expostas nas plataformas utilizadas pelos instrumentos informativos, estudados no presente trabalho. No SNIS os dados apresentados são auto declarados e por isso, atribuiu-se uma qualidade inferior, para estes dados. No entanto, há de se destacar que tal instrumento, realiza uma coleta de informações primárias e, com base nelas, calcula seus indicadores. Ou seja, não sãocoletados indicadores já calculados pelos prestadores de serviços. No caso do Trata Brasil, em geral, as informações veiculadas são obtidas por meio de levantamento de dados secundários, isto é, que não foram coletados pelo próprio Instituto. A exemplo desses dados, a plataforma apresenta informações obtidas pelo Instituto Brasileiro de Geografia e Estatística (IBGE), pelo próprio SNIS, Organização Mundial da Saúde (OMS), Fundo das Nações Unidas para a Infância (UNICEF), dentre outros.

A elaboração dos materiais dispostos na plataforma do Atlas Esgotos, contou com a parceria da SNSA/MCidades, representantes de órgãos federais, estaduais e municipais, para a consolidação de sua metodologia, coleta e validação dos dados. Em função do esgotamento sanitário ser realizado por diferentes prestadores de serviço, o levantamento das informações dos municípios foi feito a partir de dois grupos. No grupo 1, foi reunido dados dos municípios com uma população urbana superior a 50.000 habitantes onde a prestação de serviços é considerada institucionalizadas, ou seja, por Companhias Estaduais, Autarquias Municipais e concessionárias privadas, nos quais foram levantados dados primários, através de visitas de campo e reuniões técnicas. Já no grupo 2, foram abordados municípios menores e para tanto, utilizado dados secundários obtidos a partir do SNIS, IBGE, Pesquisa Nacional de Saneamento básico (PNSB) e Pesquisa Nacional por Amostras de Domicílios (PNAD). Assim, para o Instrumento informativo em questão, foi atribuída uma qualidade superior quando comparado ao SNIS, que trabalha com dados auto declarados, e Instituto Trata Brasil que apresenta, em geral, dados secundários. Entretanto, uma vez que os dados fornecidos pelo Atlas são de 2013, pode-se considerar que há uma certa desatualização das informações. Inclusive, alguns usuários que baixaram o aplicativo, fizeram tal observação, como pode ser observado na Figura 1.
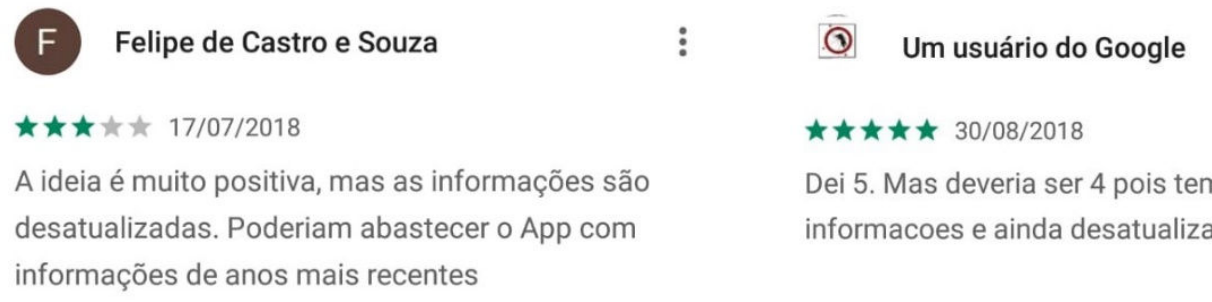

Dei 5 . Mas deveria ser 4 pois tem poucas informacoes e ainda desatualizadas.

Persp. Online: hum \& sociais aplicada., Campos dos Goytacazes, 27 (10)33-45- 2020 seer.perspectivasonline.com.br 
$\star \star \star \star \star 22 / 09 / 2018$

Seria interessante uma atualização dos dados gerais da situação das cidades e Estados. Tem cidades e Estados que as informações são referente a 2013. Pelo menos 1 por anos. Para ter um gráfico comparando o que foi feito de um ano para o outro
Um usuário do Google

$\star \star \star \star \star 01 / 11 / 2018$

Dados de 2015, nenhum acompanhamento

dos reservatórios hj. Serve pra que???? Quanto

custou???

Figura 1: Comentários sobre a falta de atualização dos dados apresentados, realizados a partir de usuários que baixaram o aplicativo Água e Esgoto. (Fonte: Play Store, 2019).

No que tange a abrangência dos instrumentos informativos abordados, é de se esperar que este item esteja diretamente relacionado com a acessibilidade. Já que a facilidade de acesso pode proporcionar maior abrangência dos meios de comunicação. Neste contexto, o SNIS por apresentar apenas sua web sitepara acesso as suas informações transmitidas e por esta não se tratar de uma ferramenta tão interativa quanto as mídias sociais, apresentou uma abrangência considerada ruim. Além disso, embora o SNIS disponibilize o Diagnostico dos Serviços de água e Esgoto, este material é de difícil absorção e abrangência para o público comum, já que possui 226 páginas, com uma apresentação considerada mais técnica e sofisticada. Pode-se considerar ainda que o Atlas Esgoto demonstrou uma abrangência superior ao SNIS, dado que, além de sua web site, possui um aplicativo no qual desde seu lançamento, em 27 de junho de 2018, a versão móbile obteve mais de 5.000 downloads (Play Store, 2019). Em termos de abrangência, o Instituto Trata Brasil, superou o SNIS e Atlas Esgoto. Visto que, além das diversas mídias utilizadas, o instituto possui alta interatividade com o público, como pode ser constatado na Tabela 2.

Tabela 2: Abrangência das mídias de comunicação utilizadas pelo Instituto Trata Brasil. Fonte: Trata Brasil, 2019

\begin{tabular}{|c|c|c|c|}
\hline Mídia social & Usuários/ seguidores & Publicações & Interação \\
\hline Blog & Não se aplica & $\square 100$ postagens & $\mathrm{n}^{\circ}$ total não informado \\
\hline Facebook & $\begin{array}{c}17.465 \text { pessoas curtiram } \\
\text { a página }\end{array}$ & $\begin{array}{c}1.129 \text { fotos e } 71 \\
\text { vídeos }\end{array}$ & $\begin{array}{l}61 \text { reações (comentários e } \\
\text { compartilhamentos) }\end{array}$ \\
\hline Instagram & 3.722 & 295 postagens & $\begin{array}{c}\text { Em média } 2.232 \text { curtidas } \\
\text { mensais }\end{array}$ \\
\hline LinkdIn & 1.638 & $\mathrm{n}^{\circ}$ total não informado & $\mathrm{n}^{\circ}$ total não informado \\
\hline Twitter & 3.403 & $\begin{array}{c}4.636 \text { twitter }+622 \\
\text { fotos e vídeos }\end{array}$ & 100 \\
\hline YouTube & 1.400 & 1h25 vídeos & $\mathrm{n}^{\circ}$ total não informado \\
\hline
\end{tabular}

Ressalta-se ainda que o Instituto Trata Brasil, consegue também alcançar o público infantil, por meio de um jogo, denominado Game Trata City e cartilha da Turma da Monica, voltada para assuntos relacionados ao saneamento e meio ambiente, ambos disponíveis em sua web site. Além disso, em julho de 2018, o Instituto Trata Brasil, em parceria com a ViaQuatro, (concessionária responsável pela manutenção e operação da Linha 4-Amarela de metrô de São Paulo), realizou uma exposição fotográfica mostrando a realidade da falta de

Persp. Online: hum \& sociais aplicada., Campos dos Goytacazes, 27 (10)33-45- 2020 
acesso ao saneamento básico no país. A ação teve como objetivo conscientizar e mobilizar os passageiros da necessidade do acesso aos serviços de água tratada, coleta e tratamento dos esgotos e conseguintemente aumentou ainda mais a abrangência de suas informações.

Para o parâmetro divulgação, o Instituto Trata Brasil, apresentou pontuação mais elevada, quando comparado aos demais instrumentos informativos abordados. Isto porque, além da divulgação realizada em matérias publicadas em portais como G1, o Instituto ainda se utiliza de embaixadores. Em geral, este grupo é formado por ex. atletas, como Daiane dos Santos, Rico de Sousa e Lars Grael, além de professores, médicos etc., que frequentam eventos destinados a informar a população sobre o tema e consequentemente propiciam maior divulgação do Instituto. Em contrapartida percebe-se que o SNIS, não apresenta divulgação satisfatória e não foi encontrada nenhuma matéria, para este fim, publicada nos meios de comunicação. Em um cenário mais otimista, o Atlas Esgoto, teve maior divulgação, como pode ser observado na Figura 2. A efetividade das divulgações realizadas para este instrumento fica nítida nos comentários realizados, apresentados na Figura 3.

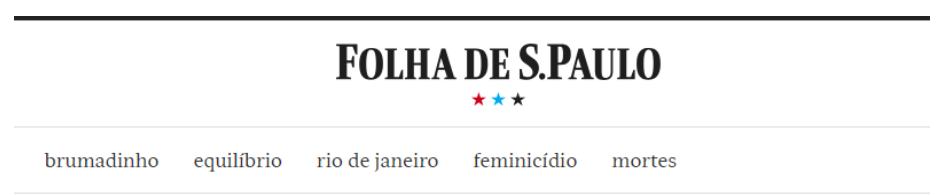

\section{Aplicativo permite a morador monitorar abastecimento de água \\ Proposta é popularizar dados de saneamento para fomentar debate}

Figura 2: Matéria publicada pela Folha de São Paulo sobre o aplicativo Água e Esgoto. (Fonte: Folha de São Paulo, 2019).

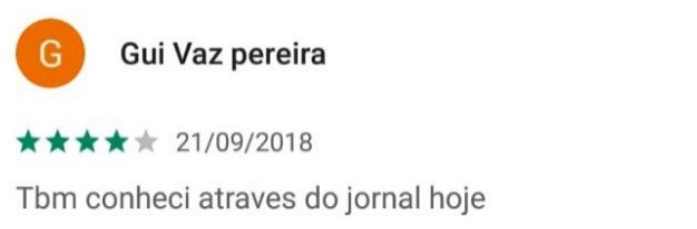 $\vdots$ aline de macedo $\star \star \star \star \star 21 / 09 / 2018$ Acabei de instalar porque vi a matéria no jornal hoje. Muito bom aplicativo dando pra acompanhar a situação de cada município assim podendo se cobrar mais dos políticos

Figura 3: Comentários que explicitam a divulgação da plataforma, realizados a partir de usuários que baixaram o aplicativo Água e Esgoto. (Fonte: Play Store, 2019).

Por fim, no que se refere a qualidade das imagens, o Instituto Trata Brasil e Atlas Esgoto, apresentam pontuação máxima, na avaliação desta variável. O Trata Brasil, apresentafiguras interativas, de fácil compreensão, que por si só exprimem o conceito desejado a ser transmitido, como é possível analisar na Figura 4. 


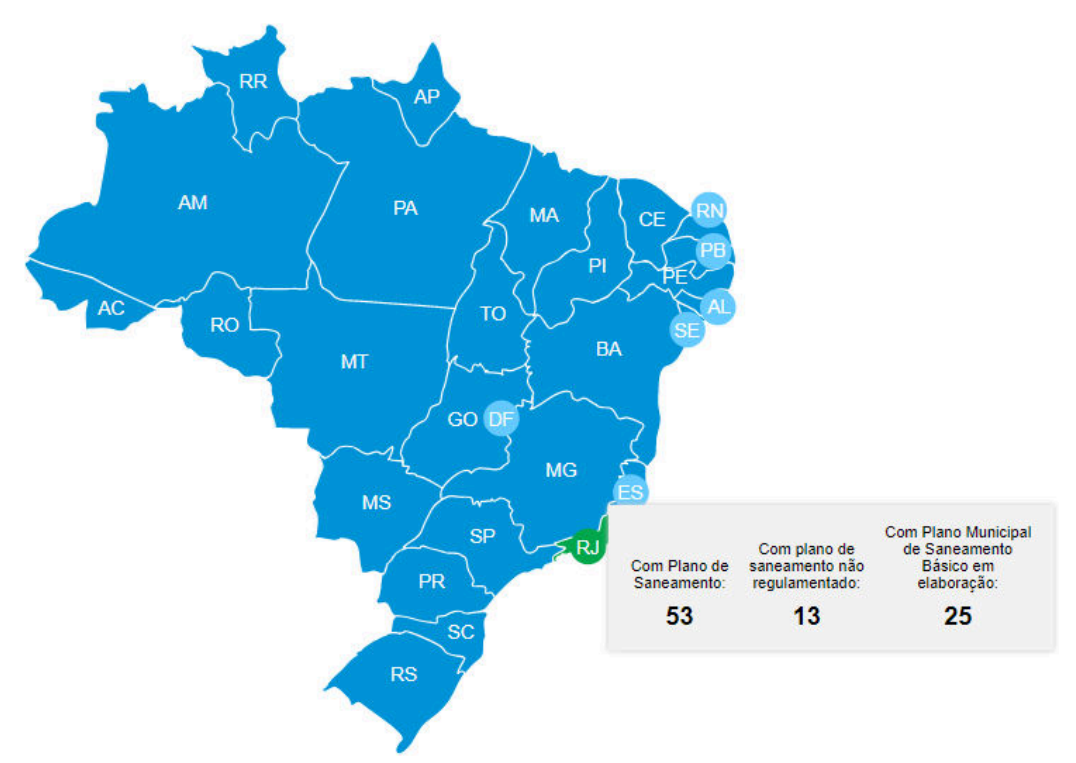

Figura 4: Imagem de ótima qualidade, disponível na web site do Instituto Trata Brasil. (Fonte: Trata Brasil, 2019).

No Atlas Esgoto, tanto em sua web site como em seu aplicativos, são disponibilizados, gráficos de fácil compreensão e croquis do fluxograma das Estações de tratamento de esgoto (ETEs) que elucidam e facilitam a compreensão do público. Assim, nas Figuras 5 e 6, podemse observar duas imagens que demonstram qualidade e clareza e por fim na Figura 7, é exibido um comentário positivo de um usuário que realizou o downloaddo aplicativo.

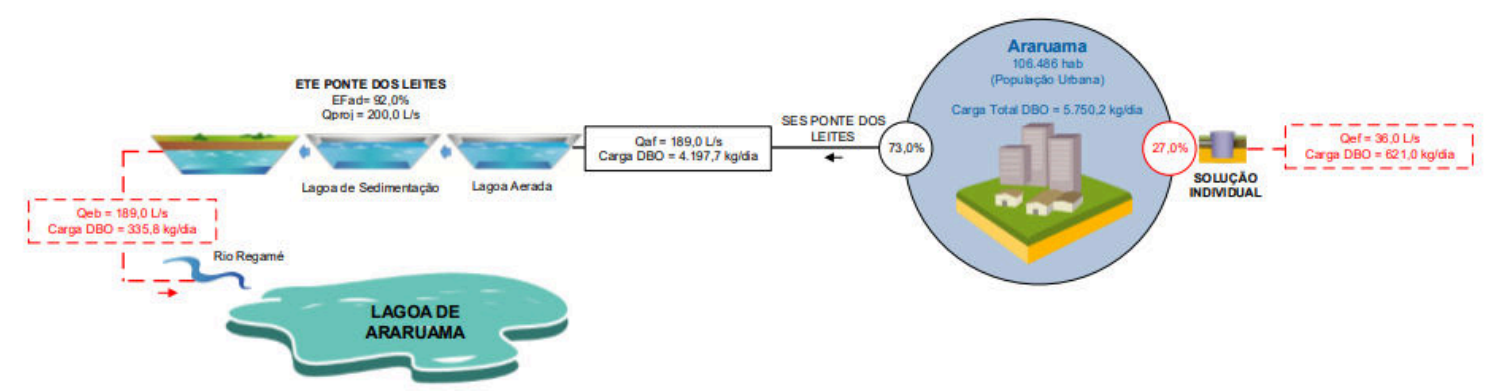

Figura 5: Croqui referente ao fluxograma de tratamento de esgotos existente no município de Araruama, disponível na web site do Atlas Esgotos e aplicativo. (Fonte: Atlas Esgoto, 2019).

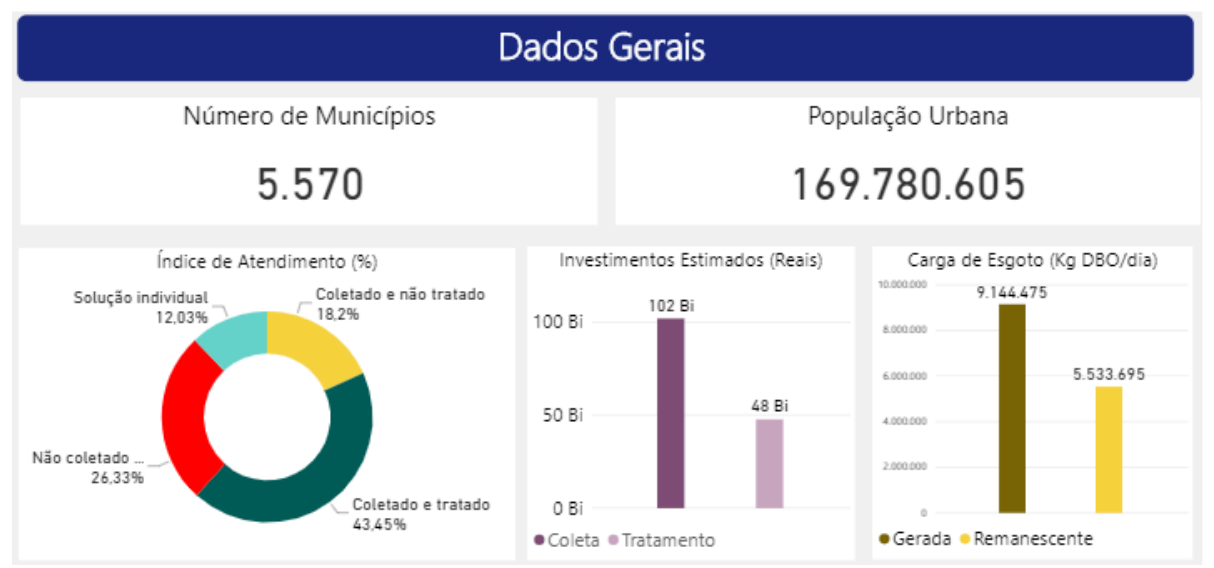

Persp. Online: hum \& sociais aplicada., Campos dos Goytacazes, 27 (10)33-45- 2020 seer.perspectivasonline.com.br 
Figura 6: Gráficos disponíveis na web site do Atlas Esgotos, no qual pode ser observada a boa qualidade da imagem.(Fonte: Atlas Esgoto, 2019).

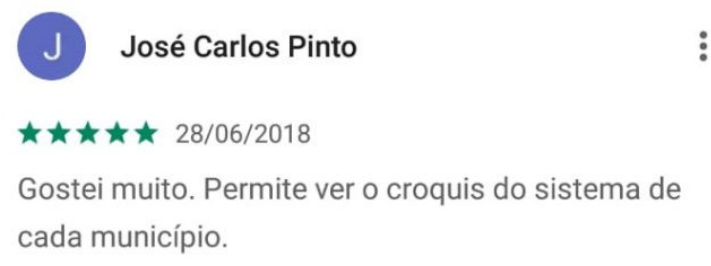

Figura 7: Comentário positivo a respeito do Croqui disponível no aplicativo de Águas e Esgoto. (Fonte: Play Store, 2019).

Em contrapartida, o SNIS não apresentou boa avaliação com relação ao parâmetro qualidade de imagem. A partir dos gráficos apresentados no Diagnostico Anual de Serviços de Água e Esgoto, disponibilizado em sua web site, pode-se afirmar que as imagens não são de fácil compreensão para população em geral. Na Figura 8, claramente pode-se constatar que o gráfico obtido pelo SNIS, não é destinado para o público que não possui um envolvimento técnico com o tema.

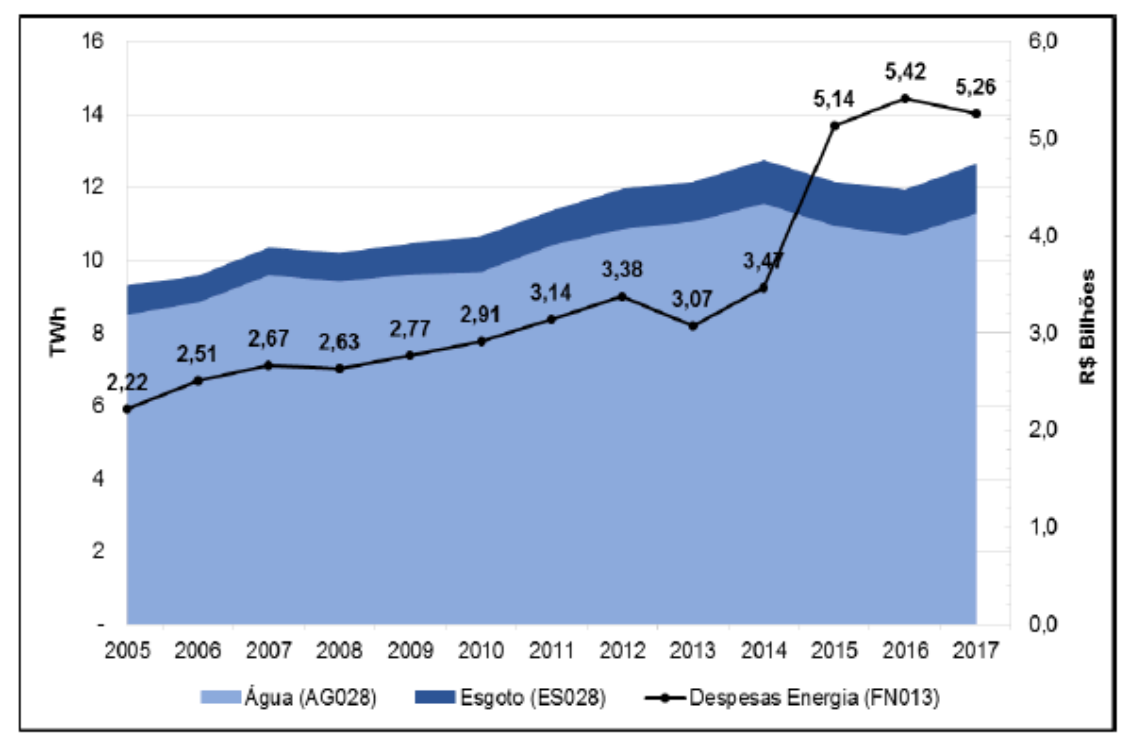

Figura 8: Gráfico apresentado no Diagnostico de Água e Esgoto, publicado pelo SNIS. (Fonte: SNIS, 2019).

\section{CONCLUSÕES}

Diante dos resultados obtidos no presente trabalho, foi possível concluir que os instrumentos informativos abordados, SNIS, Trata Brasil e Atlas Esgoto, possuem papel fundamental dentro da sociedade. Embora, as informações a respeito do Saneamento e Meio Ambiente não sejam transmitidas da mesma forma, a importância desses instrumentos em questão, são inegáveis.

Em termos gerais, o SNIS demonstrou uma certa dificuldade em propagar seus dados e estudos para o público não técnico. O sistema não faz uso de redes sociais, e se atem apenas a sua web site e materiais disponíveis para download, além de apresentar seu Diagnostico de 
Água e Esgoto de uma forma mais técnica, de difícil absorção e abrangência para a população em geral. Especialmente por utilizar uma linguagem considerada mais profissional, com gráficos menos interativos e por conter 225 páginas, das quais dificilmente o público, que não está envolvido com a área, irá ler. Assim, apesar do significado da Sigla SNIS, Sistema Nacional de Informações sobre Saneamento, este tipo de instrumento em virtude de sua baixa abrangência, não consegue atingir a população em geral e, por conseguinte não informa de maneira efetiva os cidadãos. No entanto, há de se ressaltar que os dados ofertados pela SNIS, são fundamentais para o desenvolvimento do Saneamento no território nacional e inclusive são utilizados por outros instrumentos informativos, como o Instituto Trata Brasil.

Já o Atlas Esgoto, se mostra um instrumento eficaz na promoção das informações sanitárias e ambientais. No entanto, tal instrumentos ainda possui uma linguagem técnica e por isso, pode-se considerar que atualmente está mais voltado para o meio profissional e acadêmico. Destaca-se que o Atlas Esgoto, demonstrou boa acessibilidade, abrangência, boa divulgação, gráficos interativos, croquis, além de uma ótima qualidade de dados.

O Instituto Trata Brasil por sua vez, demonstrou comprometimento e eficácia em promover a informação e conscientização da população, aos assuntos relacionados ao saneamento. $\mathrm{O}$ instituto possui alta interatividade com o público, faz uso de todas as redes sociais mais expressivas, possui linguagem acessível, gráficos de fácil interpretação, e com isso consegue atingir seus objetivos e alcançar a população em geral.

Por fim, ficou claro o entendimento que os instrumentos informativos em questão, possuem objetivos e abordagens distintas. O instituto Trata Brasil, tem o intuito de alcançar e prover a população de dados secundários e de fato atinge tal objetivo por meio de sua abordagem. Ao passo que, o SNIS aparentemente, empenha-se em promover a alimentação de dados em pesquisas e gestão, de modo a contribuir com o avanço do setor do Saneamento no Brasil. E, finalmente, o Atlas, apesar de possuir uma linguagem considerada mais técnica, quando comparado ao Instituto Trata Brasil, por meio de sua abordagem prática, pode contribuir para informar e conscientizar a população em geral e principalmente, suas informações podem fomentar pesquisas e tomadas de decisão. Neste contexto, a avaliação e pontuação refletiu os objetivos adotados por cada instrumento informativo.

Dentre os instrumentos abordados a partir da avaliação realizada no presente estudo, o SNIS apresentou a menor pontuação, com 11/24 já o Atlas esgoto obteve pontuação intermediária, com 20/24 e o Instituto Trata Brasil, exibiu a pontuação mais elevada, com 23/24. Há de se destacar que este tipo de avaliação, é importante para demonstrar que apesar do abismo do saneamento enfrentado no território nacional, existe um movimento para o desenvolvimento do setor e para isso, os veículos de comunicação são essenciais, no sentido de propiciar o maior envolvimento da população.

\section{REFERÊNCIAS}

ANA - AGÊNCIA NACIONAL DAS ÁGUAS. ATLAS Esgotos: Despoluição de Bacias Hidrográficas. Brasília. DF, 2017. Disponível em: < http://atlasesgotos.ana.gov.br/>Acesso em 16 de mar. 2019.

BRASIL. Lei $\mathrm{n}^{\mathrm{o}} 11.445$ de 5 de janeiro de 2007. Estabelece as diretrizes nacionais para o saneamento básico e para a política federal de saneamento básico. Diário Oficial da União, Brasília, 11 jan. 2007.

BRASIL, Ministério da Educação e do Desporto, Lei no 9.795 de 27 de abril de 1999. Dispõe

Persp. Online: hum \& sociais aplicada., Campos dos Goytacazes, 27 (10)33-45- 2020

seer.perspectivasonline.com.br 
sobre aeducação ambiental, institui a Política Nacional de Educação Ambiental e dá outras providências. Diário Oficial da R.epública Federativa do Brasil, Brasília, n. 79, 28 abr. 1999.

Brasil. Ministério do Desenvolvimento Regional. Secretaria Nacional de Saneamento - SNS. Sistema Nacional de Informações sobre Saneamento: Diagnóstico dos Serviços de Água e Esgotos - 2017. Brasília: SNS/MDR, 2019. 226 p. : il.

CARVALHO, R. S.; PAVAN, F. S.. Revista Perspectivas Online: Exatas e Engenharias Anais do VI CICC V. 08, $\mathrm{N}^{\mathrm{o}}$ 22, Suplemento, 2018 ISSN: 2236-885x Diagnóstico socioambiental da área de preservação ambiental da lagoa de cima. Disponível em:< https://ojs3.perspectivasonline.com.br/exatas_e_engenharia/article/view/1558>. Acesso em: Fev. 2020.

GOMES, P. Aplicativo permite a morador monitorar abastecimento de água. Folha de São Paulo, Rio de Janeiro, 28 jun 2018.Disponível em: $<$ https://www1.folha.uol.com.br/cotidiano/2018/06/aplicativo-permite-a-morador-monitorarabastecimento-de-agua.shtml $>$ Acesso em 16 de mar. 2019.

Instituto Trata Brasil. Perfil. São Paulo. Facebook: Instituto Trata Brasil . Disponível em: $<$ https://www.facebook.com/InstitutoTrataBrasil/?ref=br_tf\&epa=SEARCH_BOX $>$ Acesso em 16 de mar. 2019.

Instituto Trata Brasil. Perfil. YouTube: Instituto Trata Brasil. Disponível em: $<$ https://www.youtube.com/channel/UC-5yZUbpmxSwvDMijIbdy4w>Acesso em 16 de mar. 2019.

Instituto Trata Brasil. Perfil. Instagram: Instituto Trata Brasil. Disponível em: $<$ https://www.instagram.com/tratabrasil/?hl=pt-br>Acesso em 16 de mar. 2019.

Instituto Trata Brasil. Perfil. Twitter: Instituto Trata Brasil. Disponível em: $<$ https://twitter.com/InstTrataBrasil?ref_src=twsrc\%5Egoogle\%7Ctwcamp\%5Eserp\%7Ctwgr $\% 5$ Eauthor $>$ Acesso em 16 de mar. 2019.

PAVAN, Frank de Souza; Aplicação do método de valoração contingente para mensurar a percepção sócio ambiental dos moradores que vivem no entorno da Lagoa do Vigário. Revista Perspectivas On Line Ciências Humanas e Sociais Aplicadas. 2016. Disponível em: $<$ https://ojs3.perspectivasonline.com.br/humanas_sociais_e_aplicadas/article/view/971/771>. Acesso em: Fev. 2020.

Play Store. Disponível em: < https://play.google.com/store/apps/details?id=br.gov.ana.aguaesgotos/>Acesso em 16 de mar. 2019. 